\title{
Age-Related Alterations in Neurons of the Mouse Retina
}

\author{
Melanie A. Samuel, Yifeng Zhang, Markus Meister, and Joshua R. Sanes \\ Department of Molecular and Cellular Biology and Center for Brain Science, Harvard University, Cambridge, Massachusetts 02138
}

The behavioral consequences of age-related alterations in neural function are well documented, but less is known about their cellular bases. To characterize such changes, we analyzed 14 molecularly identified subsets of mouse retinal projection neurons (retinal ganglion cells or RGCs) and interneurons (amacrine, bipolar, and horizontal cells). The retina thinned but expanded with age, maintaining its volume. There was minimal decline in the number of RGCs, interneurons, or photoreceptors, but the diameter of RGC dendritic arbors decreased with age. Together, the increased retinal area and the decreased dendritic area may lead to gaps in RGC coverage of the visual field. Axonal arbors of RGCs in the superior colliculus also atrophied with age, suggesting that the relay of visual information to central targets may decline over time. On the other hand, the laminar restriction of RGC dendrites and the interneuronal processes that synapse on them were not detectably disturbed, and RGC subtypes exhibited distinct electrophysiological responses to complex visual stimuli. Other neuronal types aged in different ways: amacrine cell arbors did not remodel detectably, whereas horizontal cell processes sprouted into the photoreceptor layer. Bipolar cells showed arbor-specific alterations: their dendrites sprouted but their axons remained stable. In summary, retinal neurons exhibited numerous age-related quantitative alterations (decreased areas of dendritic and axonal arbors and decreased density of cells and synapses), whereas their qualitative features (molecular identity, laminar specificity, and feature detection) were largely preserved. Together, these data reveal selective age-related alterations in neural circuitry, some of which could underlie declines in visual acuity.

\section{Introduction}

Age-related alterations in neural function and behavior are well documented, but our understanding of their cellular underpinnings remains fragmentary (Hedden and Gabrieli, 2004; Burke and Barnes, 2006; Dickstein et al., 2007; Bishop et al., 2010; Glorioso and Sibille, 2011). There are at least three reasons for this discrepancy. First, the complexity of brain circuitry makes detailed structural analysis particularly difficult. Second, the marked heterogeneity of neuronal sizes and shapes can mask even dramatic changes in specific neuronal subsets. Third, a large fraction of studies have focused on pathological neural aging (e.g., Alzheimer's disease) and compared diseased and normal aged brains rather than young and old normal brains.

To partially circumvent these limitations, we have inventoried the effects of age on key morphological parameters of multiple retinal neuronal types and subtypes. The retina is arguably the best understood part of the vertebrate central nervous system with regard to its cellular patterning, circuitry, and function. It is composed of five major neuron types: photoreceptors that detect light, interneurons (horizontal, bipolar, and amacrine cells) that process visually evoked signals, and retinal ganglion cells (RGCs) that integrate this information and send it to the brain (Sanes and Zipursky, 2010). Retinal neurons can be further subdivided into

\footnotetext{
Received July 12, 2011; revised Aug. 29, 2011; accepted Sept. 15, 2011.

Author contributions: M.A.S., M.M., and J.R.S. designed research; M.A.S. and Y.Z. performed research;M.A.S. and Y.Z. analyzed data; M.A.S. and J.R.S. wrote the paper.

This work was supported by grants from the NIH to J.R.S and M.M. M.A.S. was a Damon Runyon Fellow supported by the Damon Runyon Cancer Research Foundation (DRG-1990-08). We thankZ. He for rAAV-Cre, K. Kuchibohtla and B. Bacsai for the PAAV-CAG-YC3.6 vector, and I. Provencio for antibody to melanopsin.

Correspondence should be addressed to Joshua R. Sanes, Department of Molecular and Cellular Biology, Center for Brain Science, Harvard University, 52 0xford Street, Cambridge MA 02138. E-mail: sanesj@mcb.harvard.edu.

DOI:10.1523/JNEUROSCI.3580-11.2011

Copyright $\odot 2011$ the authors $\quad 0270-6474 / 11 / 3116033-12 \$ 15.00 / 0$
}

$\sim 70$ distinct functional subtypes, a number comparable to that of other brain regions (Masland, 2001). Only in the retina, however, are markers available for a substantial fraction of these subsets. These reagents allow analysis of the impacts of aging on all of the major neuron types in a circuit.

Importantly, visual function clearly declines with age. Indeed, the majority of apparently "disease-free" individuals experience some degree of age-associated decline in vision (Spear, 1993). At least some age-related changes, including reductions in visual acuity, spatial contrast sensitivity, and motion sensitivity, cannot be attributed to optical changes. These defects are therefore likely to reflect changes in neurons, including those of the retina. The retina is also the site of diseases for which age is a major risk factor, including macular degeneration and glaucoma (Jackson and Owsley, 2003).

In this paper, we report a comparison of all major retinal neuronal types and multiple subtypes in young adult (3-5 months old) and aged (24-28 months old) mice. The number of neurons in defined populations changed little with age. However, total retinal area expanded and RGC dendritic arbors shrank with age, so that each RGC covered a decreased fraction of the visual field in old animals. In addition, the size and complexity of RGC axonal arbors in the superior colliculus (SC) decreased with age, suggesting that transmission of visual signals to the brain may be compromised. In contrast, RGC dendrites and the interneuronal processes that synapse on them remained lamina restricted, and electrophysiological responses of multiple RGC subtypes were generally preserved. Finally, we show that amacrine, bipolar, and retinal ganglion cells exhibit distinct patterns of age-related structural changes. Together, our results demonstrate selective effects of aging on particular components of neural circuitry, some of which may contribute to reduced visual function in old individuals. 


\section{Materials and Methods}

Mice. Young adult (3-5 months) and old (24-28 months) male and female C57BL/6 mice were obtained from the National Institute on Aging or The Jackson Laboratory or bred in our vivarium. Generation and characterization of Thyl-YFP-H (Feng et al., 2000), FSLT4-CreER (Kim et al., 2010; Kay et al., 2011), JAM-B-CreER (Kim et al., 2008, 2010), and Thyl-lox-stop-lox-YFP15 lines (Buffelli et al., 2003) have been described previously. To label BD- and J-RGCs, FSLT4-CreER (BD) or JAM-B-CreER mice (J) were mated to Thyl-lox-stop-lox-YFP15 mice, and tamoxifen dissolved in corn oil was administered to double transgenic offspring (500-1000 $\mu \mathrm{g}$ by oral gavage at $\mathrm{P} 8$ for J-RGCs or $200 \mu \mathrm{g}$ injected s.c. at P1-3 for BD-RGCs).

For adeno-associated virus (AAV)-mediated RGC labeling, young adult ( $3-5$ months) and old (24-28 months) mice were anesthetized by intraperitoneal injection of ketamine/xylazine (1.7 $\mathrm{mg} / 20 \mathrm{~g}$ ), and the subretinal space was inoculated with AAV2/2. In one set of experiments, Thy1lox-stop-lox-YFP15 mice were injected with AAV-Cre (a gift from Z. He, Children's Hospital, Boston, MA). In another set of experiments, AAV-YC3.6 (viral stocks generated by the Harvard Gene Therapy Institute) was injected into wild-type mice. YC3.6 combines YFP and CFP and is a calcium sensor (Nagai et al., 2004) but was used only for labeling purposes in this study (Hong et al., 2011). Mice were killed 5-8 weeks after infection.

All experiments conformed to NIH guidelines and were carried out in accordance with protocols approved by the Harvard University Standing Committee on the Use of Animals in Research and Teaching.

Immunohistochemistry. Mice were anesthetized with Nembutal and then perfused with PBS followed by $4 \%$ paraformaldehyde (PFA) in PBS. Eyes were collected and fixed for 30 min in PFA. For cross-section analyses, the cornea was removed and the optic cup was postfixed for $20 \mathrm{~min}$ in PFA, cryoprotected in 30\% sucrose, embedded in Tissue Freezing Medium (Triangle Biomedical), and sectioned at $20 \mu \mathrm{m}$ in a cryostat. Sections were incubated successively with blocking solution (3\% normal donkey serum and 0.3\% Triton X-100 in PBS) for $1 \mathrm{~h}$ at room temperature; primary antibodies were diluted in blocking solution for $12-14 \mathrm{~h}$ at $4^{\circ} \mathrm{C}$, and fluorophore-labeled secondary antibodies (Invitrogen) for $1-2 \mathrm{~h}$ at room temperature. For whole mount analysis, the retina was removed from the optic cup and postfixed for $20 \mathrm{~min}$ in PFA. Retinas were then incubated successively in blocking solution $(10 \%$ normal donkey serum and $0.5 \%$ Triton X-100 in PBS) for $1 \mathrm{~h}$ at room temperature, primary antibody diluted in blocking solution for at least $48 \mathrm{~h}$ at $4^{\circ} \mathrm{C}$, and fluorophore-labeled secondary antibody for $1-2 \mathrm{~h}$ at room temperature. Sections and whole retinas were mounted in Vectashield (Vector Laboratories). Retinas from 4-10 mice were analyzed in each experimental group.

The primary antibodies used in this study were directed against the following molecules: Bassoon (1:500, Enzo Life Sciences); Brn3a (1:500; Millipore); calbindin (1:2500, Swant); choline acetyltransferase (ChAT, 1:200, Millipore); Chx10 (1:300, Exalpha Biologicals); Sox9 (1:1000, Millipore); G $\gamma 13$ (1:200, Santa Cruz Biotechnology); tyrosine hydroxylase (TH, 1:100, Millipore); GFP (1:1000, Aves Labs and Millipore); glutamic acid decarboxylase (GAD) 65/67 (1:000, Millipore); melanopsin (1:5000, kind gift from I. Provencio, University of Virginia, Charlottesville, VA); protein kinase $\mathrm{C} \alpha$ (1:500, AbCam); recoverin (1:4000, Millipore); glycine transporter 1 (GlyT1, 1:5000, Millipore); syntaptotagmin2 (Syt2, 1:250, Zebrafish International
$\mathrm{B}$

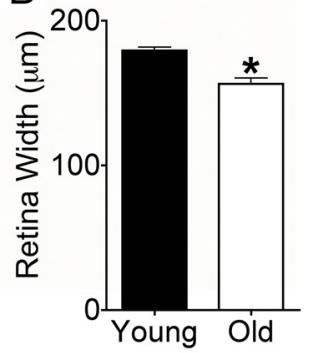

D

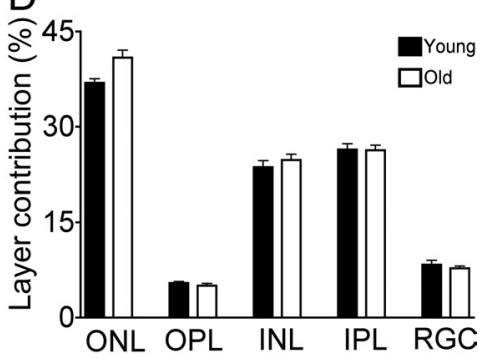

F

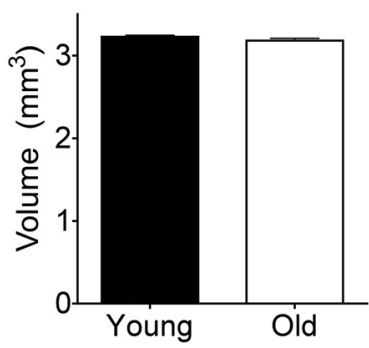

Figure 1. Decreased thickness and increased area in old retina. $\boldsymbol{A}$, Retinal sections from young adult ( 3 months) and old (26 months) mice were labeled with the nuclear marker T0-PRO-3 (blue) and the synaptic marker anti-Bassoon (green). Scale bar, 100 of flat-mounted retinas increases in old mice ( $n \geq 8$ animals per group; ${ }^{*} p<0.0001$ ). $\boldsymbol{F}$, The age-related decrease in retinal thickness is offset by the increase in total retina area such that the total volume is unchanged.

Resource Center, University of Oregon, Eugene, OR); syntaxin I (1:500, Sigma); gephyrin (1:200; Synaptic Systems); Thyl (1:500; BD PharMingen); KV4.2 (1:1000, Neuromabs, University of California at Davis and NIH); potassium/sodium hyperpolarization-activated cyclic nucleotide-gated channel 4 (HCN4, 1:500, Neuromabs); calsenilin (KChip, 1:100, Neuromabs); vGlut2 (1:500, AbCam), and vGlut3 (1:2500, Millipore Bioscience Research Reagents). TO-PRO-3, PO-PRO-1, or DAPI (Invitrogen) were used to visualize nuclei.

Histological quantification. To quantify the thickness of the retina and its nuclear and synaptic layers, images were taken at equivalent retinal eccentricities from the optic nerve head. Layer thickness was measured in 2-4 areas from each retina in 4-6 animals per group. To determine the density of cells of a given molecularly defined population, retinas were stained with the appropriate primary antibody and processed for whole mount visualization. Immunolabeled cells were quantified from $317 \mu \mathrm{m}^{2}$ (ChAT and vGlut3) and $636 \mu \mathrm{m}^{2}$ (melanopsin) areas. The relative area of the whole retina was determined using retinas that had been flat mounted, imaged in their entirety, and then montaged into a single graphic plane.

To determine the number of Bassoon-positive puncta and synaptotagmin 2-positive terminals, retinal sections were stained and imaged at high resolution at equivalent retinal eccentricities, and the number was quantified in areas of the inner plexiform layer (IPL) from single optical sections using ImageJ. Data were collected from four mice per group. Four images per retina were analyzed, and puncta or terminals were quantified from two nonsuccessive optical sections per image stack.

FACS analysis. Retinas were dissected from young adult and old C57BL/6 mice, and single cell suspensions were generated as described 


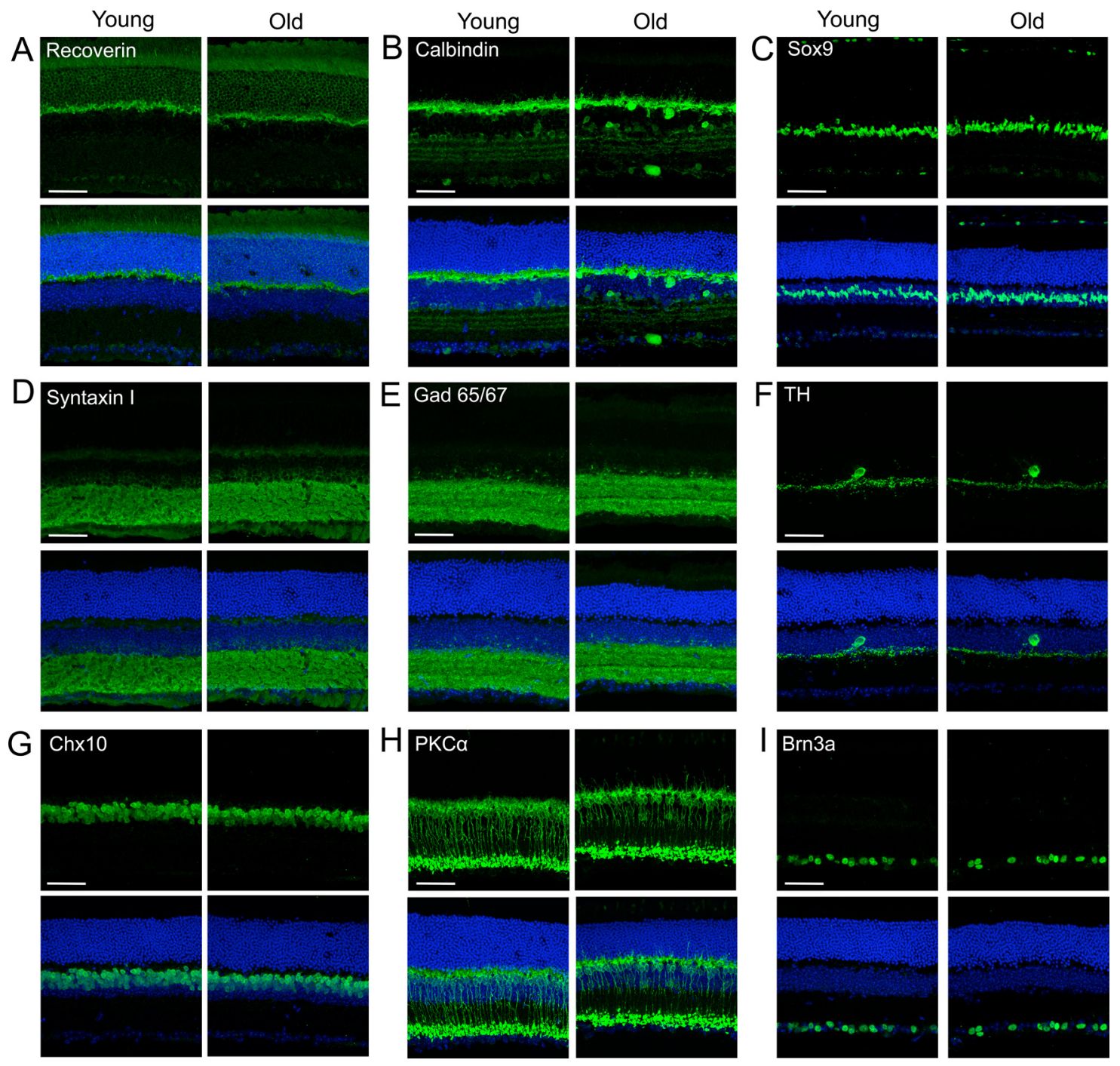

Figure 2. Neuronal types and subtypes are preserved in old retina. Retinas from young adult and aged mice were labeled with antibodies to distinct neuron types (green) and a nuclear marker (T0-PRO-3, blue). Cell types labeled were as follows. A, Photoreceptors (recoverin). B, Horizontal cells and amacrine subsets (calbindin); C, Müller glia (Sox 9). D, Amacrines (syntaxin I). E, GABAergic amacrines (Gad65/67); F. Dopaminergic amacrines (TH). G. Bipolars (Chx10). H, Rod bipolars (PKC $\alpha$ ). I, Most RGCs (Brn3a). Scale bars, $50 \mu \mathrm{m}$.

previously (Lefebvre et al., 2008). Cells were counted, fixed in 2\% PFA in PBS for 15 min on ice, and then washed in PBS. To stain for intracellular proteins, cells $\left(\sim 1.5 \times 10^{6}\right.$ per sample $)$ were permeabilized with a $0.1 \%$ $(\mathrm{w} / \mathrm{v})$ saponin solution in Hanks Balanced Salt Solution on ice for 15 min, spun, resuspended in Minimal Essential Medium [MEM-Earle's (Invitrogen) containing $0.4 \%$ bovine serum albumin and DNase (13 $\mathrm{U} / \mathrm{ml}$, Sigma)], and incubated with the indicated primary antibodies overnight at $4^{\circ} \mathrm{C}$. Cells were then washed and labeled with fluorophoretagged secondary antibodies for $1 \mathrm{~h}$ on ice. Data were collected using a FACSCalibur flow cytometer and analyzed using CellQuest software (Becton Dickinson).

$R G C$ analysis. Retinas were harvested and fixed as described above, stained with antibodies to GFP and ChAT, and mounted. Individual RGCs were mapped and imaged at high resolution. The dendritic field area of each RGC was analyzed from maximum projection images by tracing the smallest polygon that connected the dendritic tips (Kong et al., 2005; Coombs et al., 2006). M10 RGCs in Thy1-YFP-H retinas were classified based on their lamination pattern, the shape of their dendritic arbor, and the size of the arbor area based on the parameters defined by Coombs et al. (2006).

Analysis of RGC axonal arbors. Brains from JAM-B-CreER;Thy1-loxstop-lox-YFP15, FSTL4-CreER;Thy1-lox-stop-lox-YFP15, and AAVinfected animals were postfixed overnight in $4 \%$ PFA in PBS, washed in PBS, and sectioned at $100 \mu \mathrm{m}$ using a vibratome. Sections were incu- bated successively in blocking solution (5\% normal donkey serum and $0.5 \%$ Triton X-100 in PBS) overnight, anti-GFP antibody in blocking solution for at least $48 \mathrm{~h}$ at $4^{\circ} \mathrm{C}$, and secondary antibody for $2 \mathrm{~h}$ at room temperature. Sections were mounted, and axonal arbors in the superior colliculus (SC) were imaged. RGC arbors in the SC were imaged from at least three mice per group.

Electrophysiology. Methods for electrophysiological analysis are described by Kim et al. $(2008,2010)$. Briefly, dark-adapted retinas were isolated in Ringer's solution and targeted for cell-attached recording with patch microelectrodes. Light stimuli were delivered from a computer-driven video projector through a custom-made substage lens. Receptive field centers were determined with small flashing spots. Direction selectivity was then assessed with stimuli moving through the receptive field center in eight different directions, and a direction selectivity index was calculated (Kim et al., 2010).

Statistical analysis. Data were compared using an unpaired, two-tailed Student's $t$ test unless otherwise noted and evaluated using Prism software (GraphPad).

\section{Results}

Aging changes retinal shape but volume is maintained.

The retina is composed of three cellular layers, each containing a distinct set of cell types: the outer nuclear layer (ONL), compris- 
ing cone and rod photoreceptor somata; the inner nuclear layer (INL), comprising horizontal, bipolar, and amacrine interneurons and Müller glial cells; and the ganglion cell layer, containing RGCs and displaced amacrine cells. The three cellular layers are separated from each other by synaptic layers: the outer plexiform layer (OPL) contains processes of and synapses among photoreceptors, horizontal cells, and bipolar cells, while the inner plexiform layer (IPL) contains processes of and synapses among bipolar, amacrine, and retinal ganglion cells (Wässle, 2004; Sanes and Zipursky, 2010). To examine whether aging affected the global organization or size of the layers, retinas from young adult (3-5 months old) and old (24-28 months old) mice were stained with a nuclear marker (TO-PRO-3) and a synaptic marker (anti-Bassoon antibody) (Fig. 1A). The thickness of the retina decreased $\sim 15 \%$ with age (Fig. $1 B, p<0.0001$ ). This thinning significantly affected both synaptic layers as well as the INL and ganglion cell layer (Fig. 1C). Thus, the thickness of the layers relative to one another was un-

altered (Fig. $1 D$ ). In contrast, total retinal area measured from whole mounts increased by $\sim 15 \%$ with age (Fig. $1 E, p<0.0001$ ). This increase may result from slow, continued growth of the eye: the diameter of the globe, measured in both axial and transverse planes, was $\sim 10 \%$ greater in old than in young adult mice [3.3 $\mathrm{mm}(n=6$ young adult $)$ and $3.6(n=12 \mathrm{old})]$. The increased retinal area offset the decreased retinal thickness in aged animals, such that the volume was maintained (Fig. $1 F$ ). Thus, the retina changes in shape but not volume with age.

\section{Neurons are preserved in old retina}

Since aging has been associated with the death of some neuronal types (Smith et al., 2004; Dickstein et al., 2007), we asked whether retinal neurons are lost with age. First, we used markers to label the major retinal cell types in young adult and aged mice. Antibody staining for photoreceptors (recoverin; also labels some bipolar cells), horizontal cells (calbindin; also labels some amacrines), amacrine cells (syntaxin I), bipolar cells (Chx10), Müller glia (Sox9), and RGCs (Brn3a) revealed that all neuronal populations were present in aged animals in their normal positions (Fig. $2 A-D, G, I$ ). We also used a panel of markers for neuron subtypes, including rod and Type 3 and 4 cone bipolar cells $(\mathrm{PKC} \alpha, \mathrm{HCN} 4$, and Calsenilin, respectively); glycinergic, GABAergic, starburst, glutamatergic, and dopaminergic amacrines (GlyT1, Gad65/67, ChAT, vGlut3, and TH, respectively); and S3-projecting RGCs (KV4.2; Fig. 2E, F,H, data not shown, and see below). In all cases, neuron subsets were maintained in old retina, and cells were organized properly with respect to one another. To examine cell death more globally, we stained old and young retinas for activated caspase-3, a marker of apoptosis. The number of labeled cells was low in both cases, and there was no detectable age-related difference in their frequency or distribution (data not shown).

We next developed a flow cytometry-based assay to determine the total number of neurons in different subsets. Retinas from young adult and old mice were dissociated, and cell counts were performed following Trypan blue staining to detect cells dam-
B

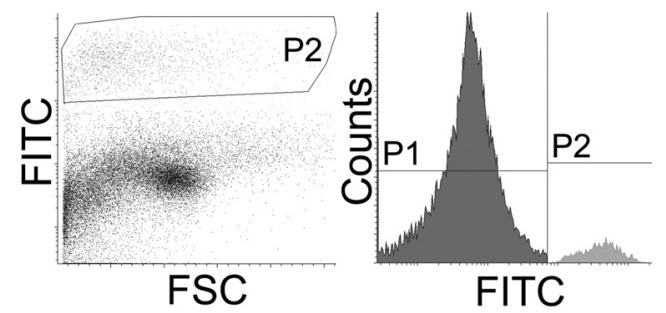

FSC FITC

Young

Figure 3. Neuronal number is maintained in old retina. Retinas from young adult and old mice were dissociated, stained with antibodies, and analyzed by flow cytometry. $\boldsymbol{A}$, Total number of cells per retina. $\boldsymbol{B}$, Flow cytometry histogram of PKC $\alpha^{+}$neurons. P2 indicates the positive population. FSC, Forward scatter. C, Number of neurons per retina for major neuronal types. Bars show the mean \pm SEM of values from five experiments.

aged during preparation. Aging had no significant effect on the total number of cells per retina (Fig. $3 A ; p=0.9$ ) or on the number of Trypan-positive cells ( $p=0.8$ ). Cells were then fixed, labeled with antibodies against the major neuronal types, and analyzed by flow cytometry (Fig. 3B). Aging did not alter the number of cells in any of the six populations tested (Fig. 3C; $p \geq$ 0.3 ). Although we cannot rule out small losses, our results indicate that neuronal death is not a major feature of retinal aging.

Together, the age-related increase in retinal area (Fig. $1 E$ ) and the stability in cell number (Fig. 3) suggested that the surface density of cells decreased with age. To test this idea, we stained retinal whole mounts with antibodies to three specific cell types: ChAT and vGlut 3 to mark amacrine subtypes and melanopsin to mark intrinsically photosensitive RGCs. We then determined the density of labeled cells at equivalent eccentricity in young adult and old mice. The density of ChAT-positive starburst amacrines in the inner nuclear and ganglion cell layer was reduced in aged mice (Fig. $4 A, B, p=0.006$ and 0.04 for the INL and GCL, respectively), but the cells remained evenly distributed as judged by quantitative assessment of their mosaic arrangement (Fig. 4C). Similar results were obtained for vGlut3-positive amacrine cells in the inner nuclear layer and for melanopsin-positive RGCs in the ganglion cell layer (data not shown).

To determine whether the decrease in cell density also affected the number of synapses within the IPL, we examined synaptic density using an antibody to Bassoon. The number of Bassoonpositive puncta decreased by $\sim 17 \%$ with age in both the $\mathrm{ON}$ and OFF sublamina (Fig. $5 A, B ; p=0.04$ and 0.003 for the ON and OFF layers, respectively). To explore the possibility that this reduction reflected a large change in specific subpopulations, we stained tissue for gephyrin, an inhibitory marker, vGlut2, an excitatory marker, and synaptotagmin 2 , which selectively marks the terminals of Type 2 and 6 bipolars (Fox and Sanes, 2007; Wässle et al., 2009). There was no apparent global reduction in the levels of gephyrin and vGlut2 (Fig. 5C,D), although it was difficult to resolve individual puncta with these stains. However, 

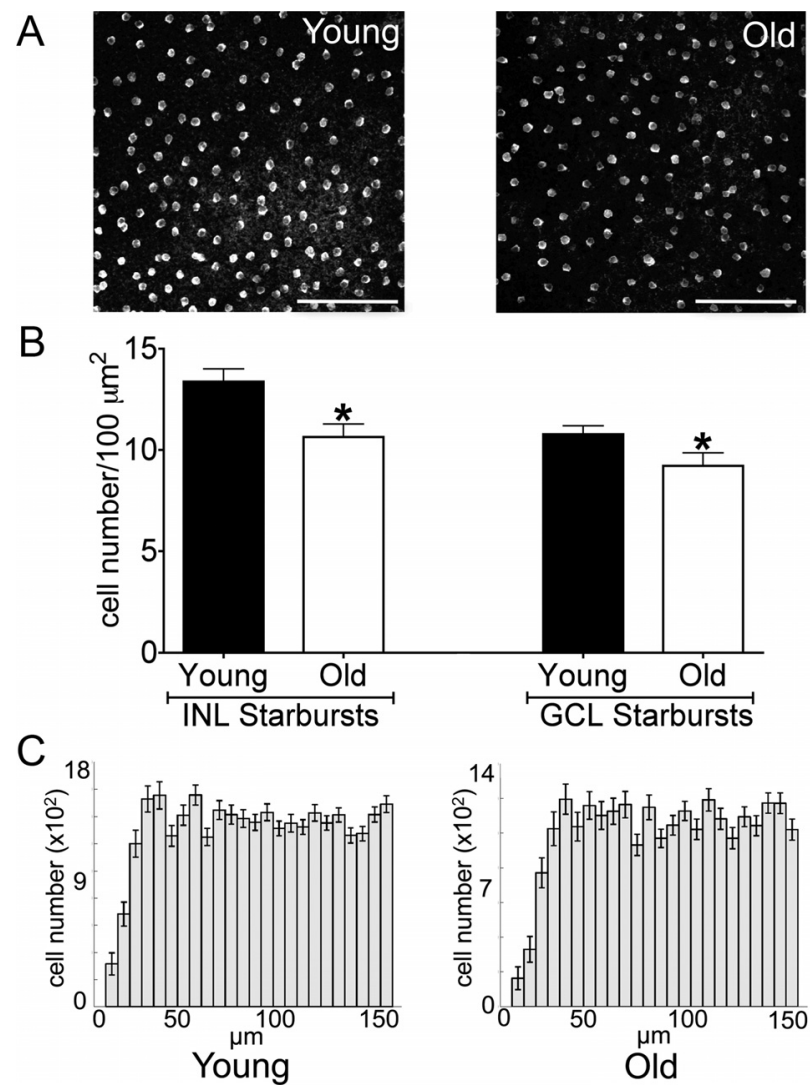

Figure 4. Decreased cell density in old retina. $\boldsymbol{A}$, Retinas from young adult and old mice were flat mounted and stained with anti-ChAT to label starburst amacrines. Images were taken in the INL. Scale bars, $100 \mu \mathrm{m}$. $\boldsymbol{B}$, Density of starburst amacrines in the ganglion cell layer $\left(\mathrm{GCL} ;{ }^{*} p=0.04\right)$ and INL $\left({ }^{*} p=0.006\right)$. Bars show the mean cell number \pm SEM from 4-8 mice. C, Density recovery profiles (Rodieck, 1991) demonstrating mosaic spacing of starburst amacrines in young adult and old retina.

terminal density counts using synaptotagmin 2 revealed a decrease of $10 \%$ that mirrored the general reductions in synapse number observed with Bassoon (Fig. $5 E$ and data not shown). These data suggest that with age fewer connections occupy a given IPL volume, and this reduction occurs across multiple synaptic types.

\section{Dendritic arbors of RGCs shrink with age}

To test whether the size or shape of neuronal arbors changes with age, we focused on two RGC subtypes, J- and BD-RGCs, which are labeled with YFP in transgenic lines that we generated and characterized previously (Kim et al., 2008, 2010; Kay et al., 2011). Both are direction-selective RGCs that respond preferentially to upward motion in the visual world. J-RGCs are OFF cells with strikingly asymmetric dendritic arbors that "point" toward the ventral pole of the retina, whereas BD-RGCs are ON-OFF cells with modestly and variably asymmetric arbors. When viewed en face, the dendritic arbors of aged J- and BD-RGCs were qualitatively similar to those in young adult mice (Fig. $6 A, B, D, E$ ). For example, the striking asymmetry and ventral patterning of J-RGC arbors were maintained. In each case, however, the dendritic fields of old RGCs covered less area than those of young adult RGCs (Fig. $6 C, F ; p=0.01$ for J-RGCs and 0.04 for BD-RGCs). Because RGC dendritic area decreased with age (Fig. 6C,F) and total retinal area increased (Fig. $1 E$ ), the fraction of the retinal area occupied by an individual RGC arbor was markedly reduced in old mice (Fig. 6G,H; $p=0.0002$ and 0.005 for J and BD-RGCs, respectively). Together, these data indicate that aging may lead to
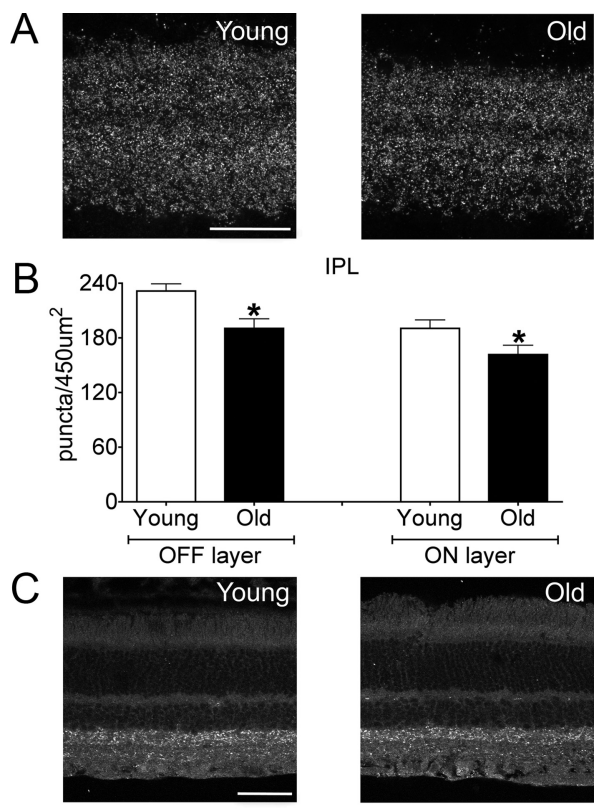

IPL
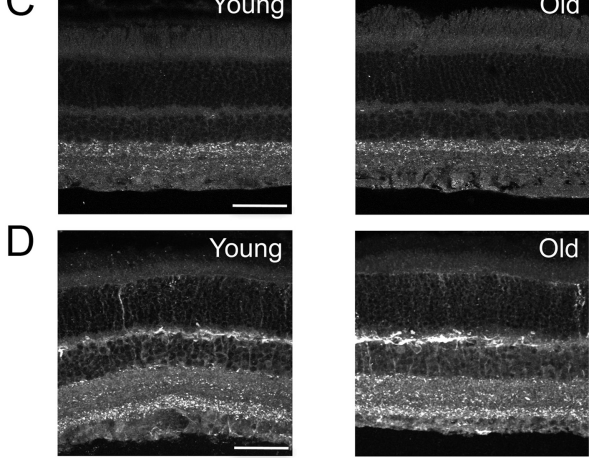

E
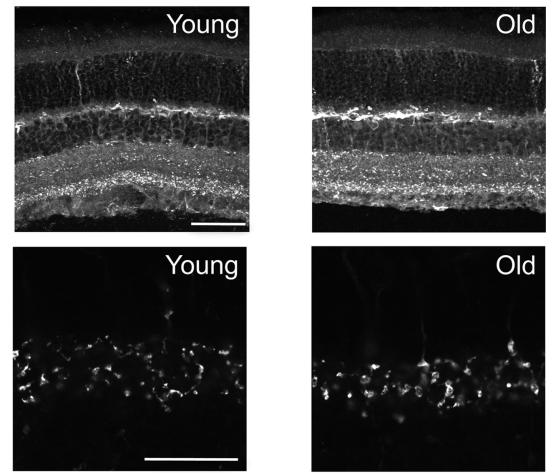

Figure 5. Decreased synaptic density in old retina. $\boldsymbol{A}$, The IPL of young adult and old mice stained for Bassoon (synaptic marker). Scale bar, $25 \mu \mathrm{m}$. B, Density of Bassoon-positive puncta in OFF $\left({ }^{*} p=0.003\right)$ and ON $\left({ }^{*} p=0.04\right)$ portions of the IPL sublaminae. $\boldsymbol{C}, \boldsymbol{D}$, Reductions in Bassoon density likely do not reflect large decreases in synaptic subpopulations, as levels of gephyrin ( $\boldsymbol{C}$, inhibitory marker) and vGlut2 ( $\boldsymbol{D}$, excitatory marker) were not globally reduced with age. Scale bars, $50 \mu \mathrm{m}$. $\boldsymbol{E}$, The IPL of young adult and old mice stained for synaptotagmin 2 , a marker of type 2 and 6 bipolar terminals. Puncta density was $10 \%$ lower in old than in young adult retina. Scale bar, $25 \mu \mathrm{m}$. Bars represent the mean \pm SEM from four mice.

decreased coverage of the visual field by RGCs of distinct functional classes (Fig. 6I).

To assess the possibility that dendritic shrinkage might be confined to just some RGC subsets, we assessed the dendritic architecture of RGCs in Thyl-YFP-H animals (Fig. 7A,B). Approximately $200 \mathrm{RGCs}$ per retina are YFP positive in this line, and previous studies have shown that the YFP-positive RGCs include most, if not all, of the $\sim 20$ RGC subtypes that can be distinguished by morphological criteria such as lamination pattern and dendritic area (Coombs et al., 2006). The number of labeled RGCs per retina in the YFP-H line did not significantly differ between young adult and old animals $(n=211 \pm 38$ and $205 \pm$ 41 for young and old, respectively), consistent with the finding that neuronal loss is not a feature of retinal aging (Fig. 3). Aging was, however, associated with a reduction of $\sim 20 \%$ in RGC soma size (Fig. $7 C ; p=0.0002$ ) and a reduction of $\sim 13 \%$ in dendritic field area (Fig. $7 D ; p=0.008$ ). As a result of the decrease in dendritic field area, the largest RGCs in young adult retinas were larger than any in old retina, the smallest RGCs in old retina were smaller than any in young adult retinas (Fig. $7 E$ ), and the fraction 

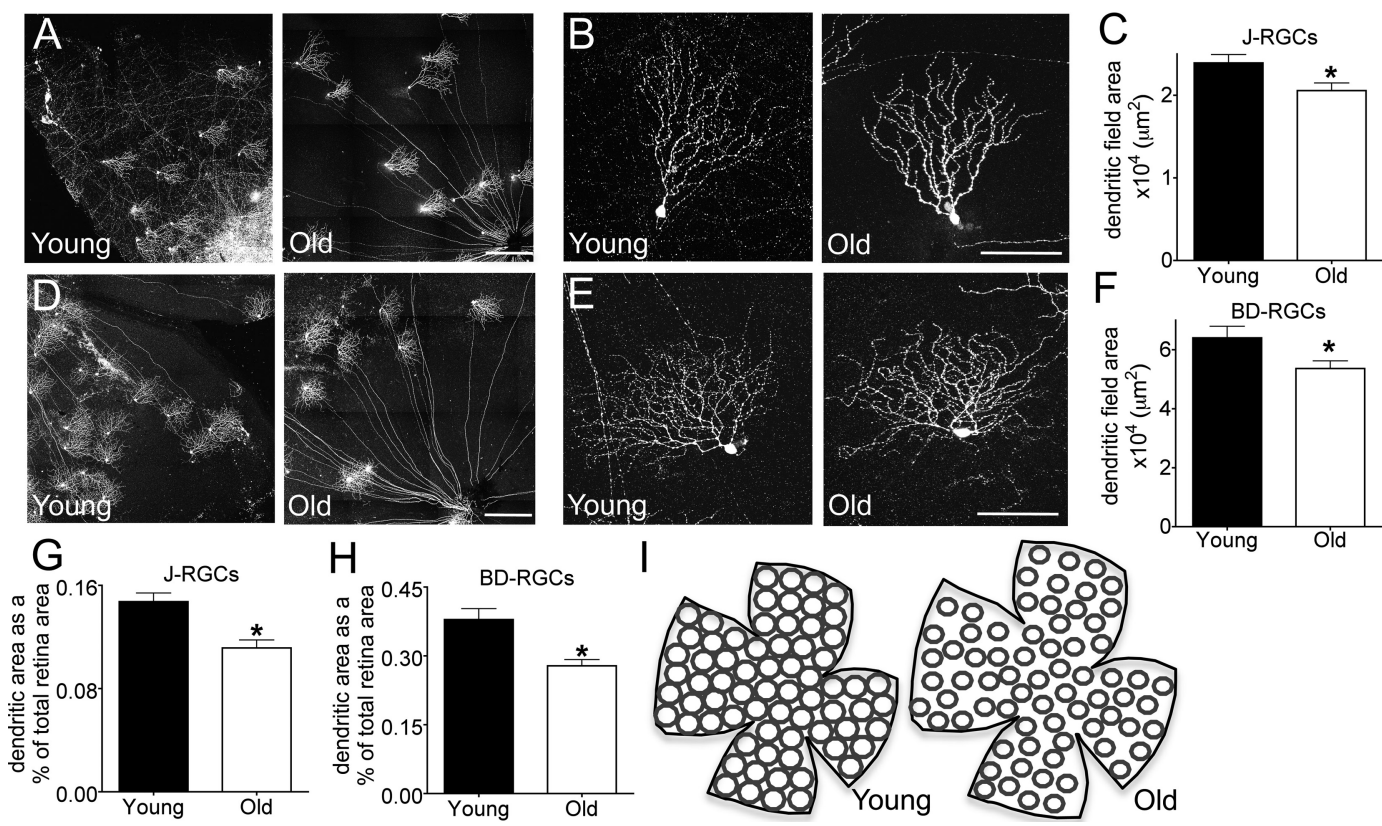

Figure 6. Aging reduces RGC dendritic arbor diameter. $A, B, J-R G C s$ labeled with YFP were imaged in young adult and old mice. Arbor asymmetry was maintained with age. $\boldsymbol{C}$, Total dendritic field area of J-RGCs was reduced with age ( $n=36$ young, 39 old; $\left.{ }^{*} p=0.01\right) . \boldsymbol{D}, \boldsymbol{E}, \mathrm{BD}-\mathrm{RGCs}$ labeled with YFP. $\boldsymbol{F}$, Total dendritic field area of BD-RGCS was reduced with age $\left(n=30\right.$ young, 150 old; ${ }^{*} p=$ 0.04). $\mathbf{G}, \boldsymbol{H}$, Dendritic field area expressed as a percentage of the total retinal area for J-RGCs $\left(\boldsymbol{G},{ }^{*} p=0.0002\right)$ and BD-RGCs $\left(\boldsymbol{H},{ }^{*} p=0.0005\right)$. The increase in total retina area amplifies the affect of age-related reductions in dendritic field size. I, Sketch showing that the increase in total retina area plus the reduced dendritic diameter could lead to incomplete coverage of the visual field by some RGC subtypes and decreased overlap for others. Scale bars: $A, D, 300 \mu \mathrm{m} ; \boldsymbol{B}, \boldsymbol{E}, 100 \mu \mathrm{m}$.

of the retinal area covered per arbor was significantly reduced (Fig. $7 F$ ).

Among the RGC subtypes labeled in the YFP-H line, one readily recognizable group comprised the ON $\alpha$-like RGCs (Fig. 7G), which have been described in several species (Peichl et al., 1987) and were termed cluster M10 by Coombs et al. (2006), cluster 9 by Badea and Nathans (2004), and cluster 11 by Kong et al. (2005) in mice. The dendritic area of M10 RGCs is among the largest of all RGC types (Coombs et al. 2006) and, like that of J- and BDRGCs and randomly labeled RGCs, decreased significantly in old mice (Fig. $7 H ; p=0.0004$ ). Together with our evidence that RGCs are preserved with age, these data suggest that the global reduction in dendritic field area does not result from the selective loss of large field RGCs. Rather, dendritic shrinkage and a reduction in the fraction of the retina covered by each dendritic arbor appear to be general features of old RGCs.

\section{Arbors of RGCs and their inputs remain lamina specified in old retina}

The dendrites of RGCs are confined to one (monostratified) or two (bistratified) sublaminae within the IPL, and the visual features to which RGC subtypes respond depend in large part on the inputs they receive from specific subtypes of amacrine and bipolar cells in these sublaminae (Wässle, 2004; Sanes and Zipursky, 2010). To ask whether the dendrites of RGCs remain confined to appropriate sublaminae in old retina, we examined sections from transgenic mice in which J- and BD-RGCs were labeled. In young adults, J-RGCs send their dendrites to lamina S1 of the IPL, while BD-RGCs laminate at the outer margin of S2 and S4. RGC dendritic targeting was maintained in old retina (Fig. $8 A, B$ ). Dendrites occasionally extended beyond appropriate sublaminae, but the incidence of this apparent mistargeting did not differ significantly between young adult and old retina ( 3 mistargeted neurites from 17 young adult J-RGCs and 4 mistargeted neurites from 16 aged J-RGCs). We also used an antibody to melanopsin to label two populations of intrinsically photosensitive RGCs, the M1 cells, which send their dendrites to outermost layer of the IPL (S1), and the M2 cells, whose dendrites are confined to the proximal IPL (S4-S5) (Provencio et al., 2002; Berson et al., 2010). Again, dendrites remained confined to appropriate sublaminae in old retina (Fig. 8C). Thus, the laminar specificity of RGC dendrites is not detectably degraded with age.

In parallel, we asked whether arbors of amacrine and bipolar cells, which synapse on RGC dendrites, remain lamina specified in old mice. The sublaminar targeting of starburst amacrines (visualized with anti-ChAT antibody; arborize at the outer margin of S2 and S4, and vGlut3-positive amacrines (S2 and S3) remained precise in old retina (Fig. $8 D$, and data not shown). Likewise, synaptotagmin 2 staining of Type 2 and 6 OFF bipolars, $\mathrm{G} \gamma 13$ staining of rod and cone ON bipolars and PKC $\alpha$ staining of rod bipolars (Wässle et al., 2009), showed that ON/OFF and segregation in the IPL remains intact with age (Figs. $8 \mathrm{E}$ and $2 \mathrm{H}$ ). Thus, laminar restriction of both presynaptic and postsynaptic partners in the IPL is maintained over time.

In contrast to the stability of bipolar axons, laminar restriction of bipolar dendrites was compromised with age. Consistent with previous reports (Liets et al., 2006; Eliasieh et al., 2007; Terzibasi et al., 2009), PKC $\alpha$-positive dendrites of rod bipolars extended beyond the confines of the OPL into the ONL in old mice (Fig. $8 F)$. These sprouts appeared at $\sim 1$ year and increased in number over the following year. Horizontal processes in the OPL also sprouted in old mice (Fig. $8 \mathrm{G}$ and Liets et al., 2006; Eliasieh et al., 2007; Terzibasi et al., 2009).

\section{Function is preserved in old RGCs}

The responses of RGCs to visual features provide a sensitive measure of the integrity of retinal circuitry, since they result from information processing by interneurons as well as intrinsic properties of RGCs. We therefore used fluorescence optics to identify $\mathrm{J}$ - and BD-RGCs in retinal explants from young adult and aged 

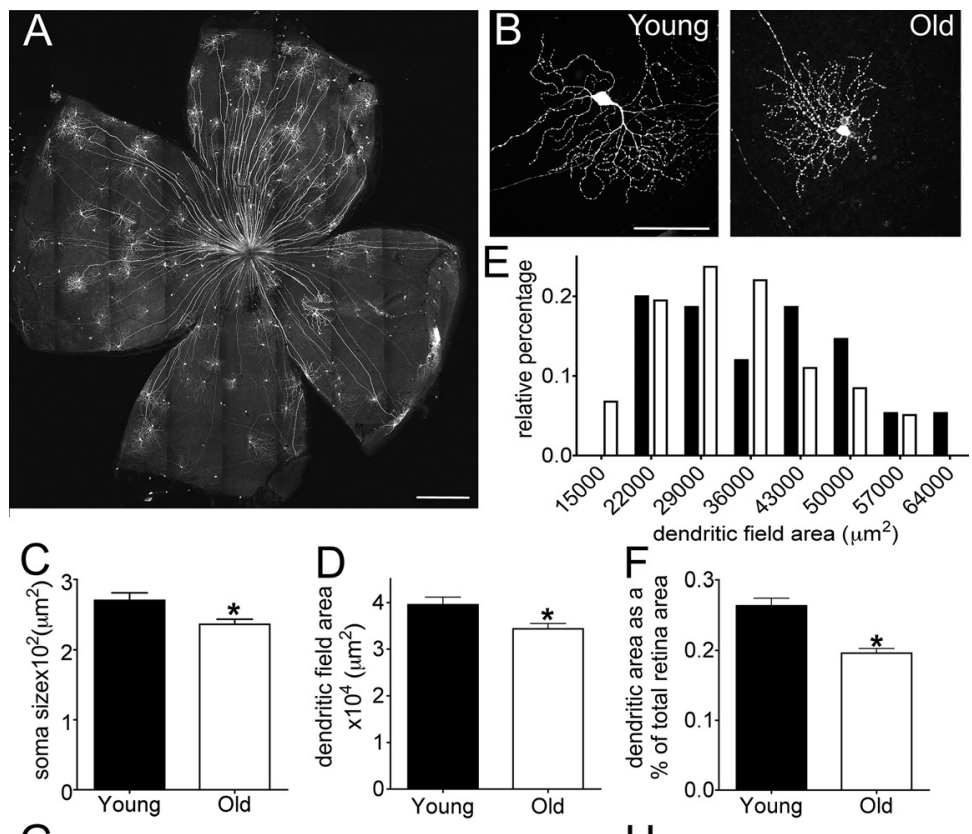

endritic field area $\left(\mu \mathrm{m}^{2}\right)$

G
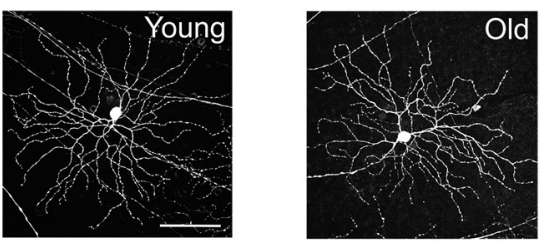

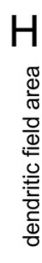

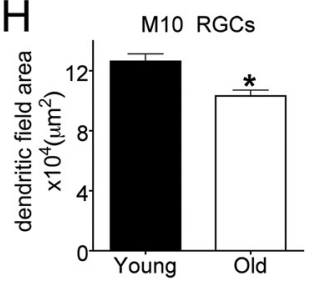

$9 E, F)$. To compare the direction selectivity of multiple old and young J- and BDRGCs, we calculated a direction selectivity index as described by Kim et al. (2010). Data from a nondirection selective RGC type, W3 (Kim et al., 2010), were included for comparison. No statistically significant differences in direction selectivity were observed between young and old J-RGCs or between young and old BDRGCs, although there was a tendency for old J-RGCs to be slightly attenuated in their direction-selectivity (Fig. 9G).

To extend this analysis, we assessed the response properties of randomly selected RGCs, which would be expected to include members of multiple subtypes. Old RGCs showed a normal array of physiological properties, including transient $\mathrm{ON}$, sustained $\mathrm{ON}, \mathrm{ON}-\mathrm{OFF}$, transient OFF, and sustained OFF responses (Fig. $9 H$ ). In addition, cells showed appropriate surround inhibition as indicated by decreased responses to spots of increasing size (Fig. 9I). Although we cannot rule out small differences in the physiological properties of old RGCs, these data suggest that normal light responses are maintained in most if not all RGC subtypes.

\section{Aging reduces RGC axon terminal density in the brain.}

Figure 7. Decreased dendritic arbor diameter in randomly labeled RGCs. $A, B, R G C s$ from young adult and old YFP-H mice.
shows a whole retina from an old mouse, and $B$ shows single RGCs at high power. $C, R G C$ soma size ( $n=84$ young adult and 124 old RGCs; $\left.{ }^{*} p=0.003\right)$. $\boldsymbol{D}$, Dendritic field area ( $n=88$ young adult and 133 old RGCs; $\left.{ }^{*} p=0.008\right)$. E, Distribution of dendritic field areas in young adult and aged mice. $\boldsymbol{F}, \mathrm{RGC}$ dendritic field area expressed as a percentage of the total retinal area ( ${ }^{*} p<0.0001$ ). $\boldsymbol{G}, \mathrm{M} 10 \mathrm{ON}$ RGCs as identified by dendritic shape and lamination. $\boldsymbol{H}$, The dendritic field area of $\mathrm{M} 10$ cells was reduced with age ( $\left.^{*} p=0.004\right)$. Scale bars, $\boldsymbol{A}, 500 \mu \mathrm{m} ; \boldsymbol{B}, \mathbf{G}, 100 \mu \mathrm{m}$.

mice and recorded their physiological properties. When a stationary flashing spot is positioned over the receptive field center of a young adult BD-RGC, increasing the spot size first induces greater responses and then decreases the response rate, indicating the presence of a concentric excitatory center and inhibitory surround regions (Kim et al., 2010). Similar results were obtained from old BD-RGCs, indicating that center-surround organization is preserved with age in these cells (Fig. 9A). Old J-RGCs also maintained their characteristic response properties to flashing spots (Kim et al., 2008), first increasing and then decreasing their firing rate as a function of spot size at light offset and firing at light onset only when the spot size was large (Fig. 9B). From these results, we infer that the lateral inhibition responsible for centersurround organization is preserved in old retina. Moreover, there was no significant difference between young and old cells for either J- or BD-RGCs in the spot size that elicited the maximal response (data not shown); the failure to observe a significant age-related decrease in receptive field area is not surprising given the small difference in arbor size documented above.

Both $J$ and BD-RGCs are selectively responsive to motion directed ventrally on the retina (Kim et al., 2008, 2010). We assessed direction selectivity of J- and BD-RGCs in old retina with small spots moving in different directions. The firing rate of old J- and BD-RGCs varied strongly with the direction of motion (Fig. 9C, $D$ ). Like those in young retinas, old BD-and J-RGCs responded best to stimuli moving from the dorsal to ventral direction (Fig. and Dräger, 1985; Mooney and Rhoades, 1990), with individual RGC types displaying distinct arbor morphologies and occupying different strata within the retinorecipient zone (Huberman et al., 2009; Kim et al., 2010; Hong et al., 2011). To assess the axonal arbors of aged RGCs in the SC, we examined axons of J- and BD-RGCs. The axons of both of these RGC populations form complex, distinctive arbors that laminate in the superficial half of the SC. With age, J-RGC and BD-RGC axons maintained appropriate SC laminar targeting (Fig. 10A,B), but for both cell types the density of terminal branches within the arbor appeared to decrease (Fig. 10C,D), and in a few cases segments of old axons were abnormally distended (data not shown). Aging also resulted in a small but significant decrease in the axon height of both groups (Fig. $10 E, p \leq 0.002$ ). The most dramatic change, however, was a $\sim 30 \%$ decrease in axon terminal area (Fig. 10F, $p \leq 0.001$ ). Reduced axonal density and terminal area may be associated with a decreased ability of RGCs to transmit visual information to the brain.

\section{Reduction in RGC arbors size results from age, not YFP expression}

YFP is generally nontoxic to neurons (Feng et al., 2000), but prolonged expression of high YFP levels has been reported to have deleterious effects on the structure of some (Bridge et al., 2009) but not all (Valdez et al., 2010) neuronal types. It was therefore necessary to determine whether the decrease in RGC dendritic and axonal arbor size in old mice might be a conse- 

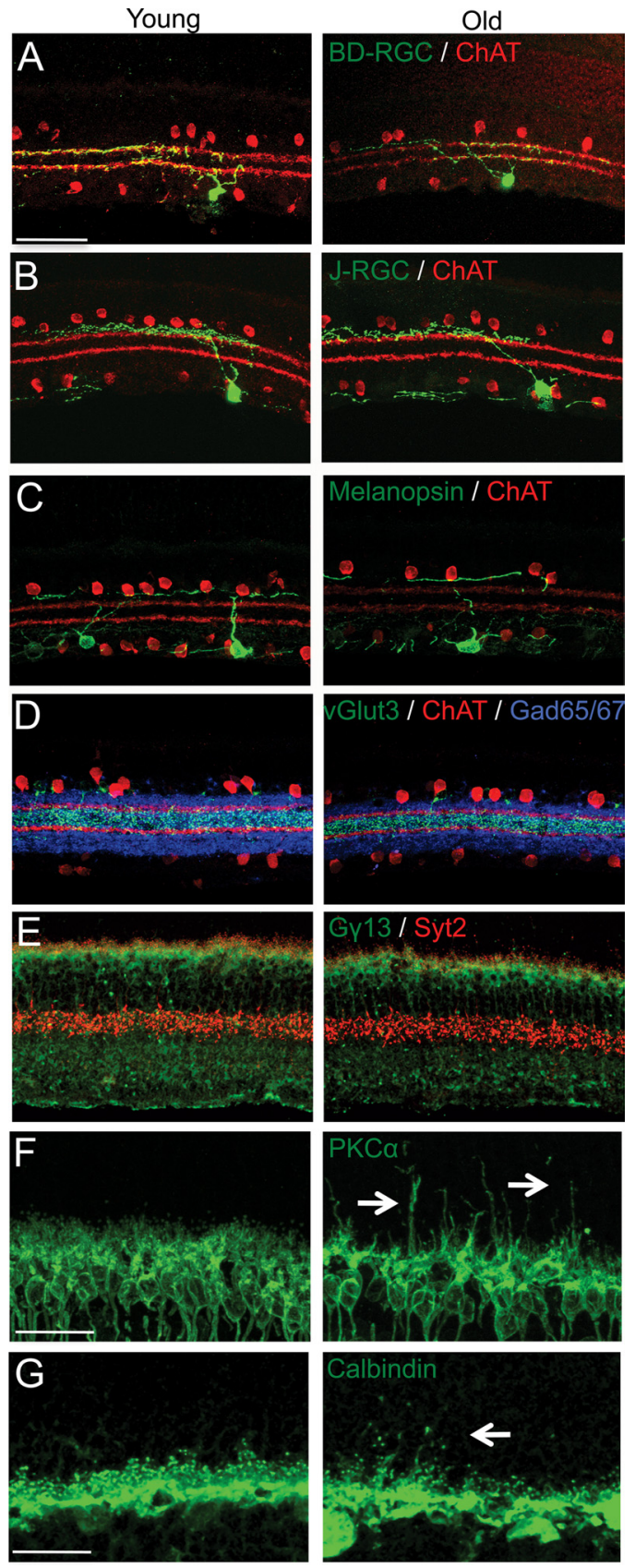

Figure 8. IPL lamination is intact in old mice. $\boldsymbol{A}-\boldsymbol{F}$, Sections of young adult retina and old retina were immunostained to label subsets of processes in the IPL. Scale bar, $50 \mu \mathrm{m}$. The outer margins of $\mathrm{S} 2$ and $\mathrm{S} 4$ are marked with anti-ChAT antibody (red) in $\boldsymbol{A}-\boldsymbol{D}$. $\boldsymbol{A}, \mathrm{GFP}$-positive dendrites of a BD-RGC in S2 and 4. B, GFP-positive dendrites of a J-RGC in S1. C, Melanopsin-positive RGC dendrites in S1. D, vGlut3-positive amacrine dendrites in S3 (green) and GABAergic amacrines (blue). $\boldsymbol{E}$, Synaptotagmin-2-positive Type 2 bipolar axons in the outer IPL and (red) and G $\gamma$ 13-positive 0N-bipolar axons in the inner IPL (green). $\boldsymbol{F}, \mathbf{G}$, Sections were immunostained to label processes in the OPL. Scale bar, $25 \mu \mathrm{m}$. $\boldsymbol{F}$, PKC $\alpha$-positive rod bipolar cells (green) extend dendrites into the ONL in old mice (arrows). G, Calbindin-positive horizontal cell neurites (green) also send ectopic processes into the ONL (arrows) with age.

quence of long-term YFP expression rather than aging per se. To assess this possibility, we labeled RGCs in young adult and aged mice with recombinant adeno-associated virus or AAV (see Materials and Methods) and then assessed dendritic architecture 1-2 months after infection. RGCs labeled in this way showed reductions in dendritic field area (Fig. $11 A, B, p=0.03$ ) and soma size (Fig. $11 C, p=0.04$ ) similar to those that had expressed YFP for $\geq 2$ years, indicating that these alterations are a consequence of aging rather than of prolonged YFP expression.

We also imaged individual axonal arbors in the superior colliculus of mice that had received a retinal AAV injection. Compared to the arbors of young adult RGCs, old RGC arbors showed an obvious reduction in terminal size and occasionally demonstrated abnormal varicosities and dramatic decreases in branch density within the arbor (Fig. $11 D, E$ ). On average, the arbor area was reduced $\sim 10 \%$, but the large differences among RGC subtypes in axon arbor size (Hong et al., 2011) made this difference nonsignificant $(p=0.6$ ), emphasizing the value of using genetically marked lines to precisely identify the effects of aging on a given neuron population. Finally, we used AAV-infected retinas to ask whether arbors of interneurons, like those of RGCs, atrophied with age. Multiple subtypes of amacrine cells were labeled in these retinas, and the low density of labeling made it possible to image and measure their arbors. Two types of amacrines, starburst amacrines (Fig. 12A) and AII amacrines (Fig. 12B), were labeled in substantial numbers and were readily identifiable based on their distinctive morphology. The dendritic field areas of these neurons, unlike those of RGCs, did not show a detectable reduction with age (Fig. $12 C, D ; p=0.34$ for AII amacrines and 0.79 for starburst amacrines). Thus, a reduction in arbor size is not a general feature of neuron aging; instead, RGCs may be especially vulnerable.

\section{Discussion}

As a first step in elucidating how aging affects neural circuitry, we analyzed the retina. Because the retina has been well characterized in young adults, we were able to ask questions about features of aging that have been difficult to address in other systems, including: (1) Are subsets of neurons lost? (2) Do their arbors shrink, sprout or rearrange? (3) Are dendritic and axonal compartments affected differently? (4) Is the arrangement of neurons altered? (5) Do neurons change in ways that might explain agerelated functional deficits? Previous studies have asked these questions of single neuronal types or assayed all neurons in a region together. In only a few cases, however, have these questions been examined for multiple neuronal types in a defined circuit (Richard et al., 2010). By taking advantage of molecular markers for multiple subtypes, we showed striking differences in age-related structural changes, both among cell types and between axons and dendrites of single cell types.

Neuronal loss was once thought to be a general feature of "normal" aging (Miller et al., 1984; Swaab et al., 1985; Terry et al., 1987). More recent studies have found, however, that many populations are spared (Morrison and Hof, 1997; Dickstein et al., 2007). For the retina, some studies have reported age-related loss (Katz and Robison, 1986; Gao and Hollyfield, 1992; Weisse, 1995; Aggarwal et al., 2007) while others have not (Trachimowicz et al., 1981; Morrison et al., 1990; Kim et al., 1996). Some of these differences may reflect the difficulty of calculating absolute cell number from sections in cases where cell volume or density changes. We therefore devised a flow cytometry assay that was insensitive to such alterations. We detected no change in the numbers of any of the major retinal neuron types (Fig. 3).

In contrast to the maintenance of neuronal number, retinal shape and neuronal density were altered with age. Both cellular and synaptic layers thinned with age. Surprisingly, the decreased thickness was offset by an increase in retinal area. As a consequence, total retinal volume was maintained (Fig. 1), but the en face density of neurons decreased (Fig. 4). Our results are consistent with reports of reduced neuron density (Aggarwal et al., 

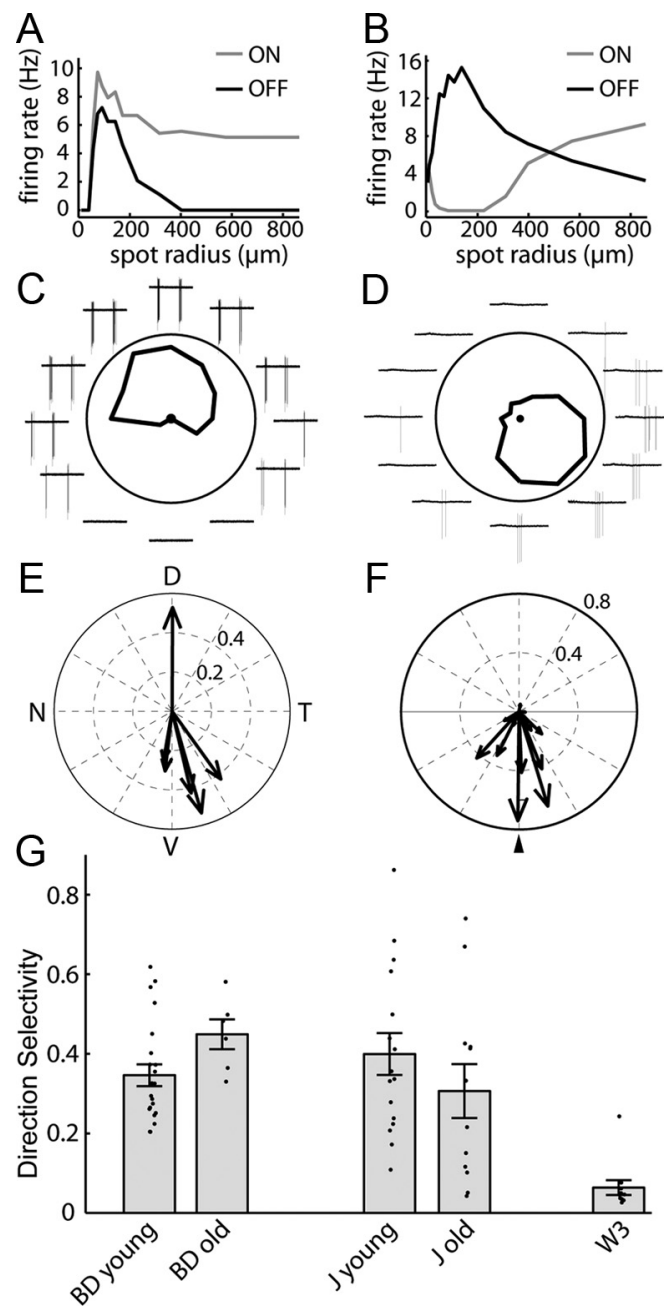

$\mathrm{H}$

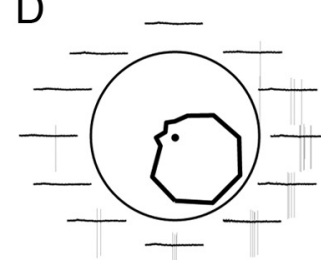

$\mathrm{F}$
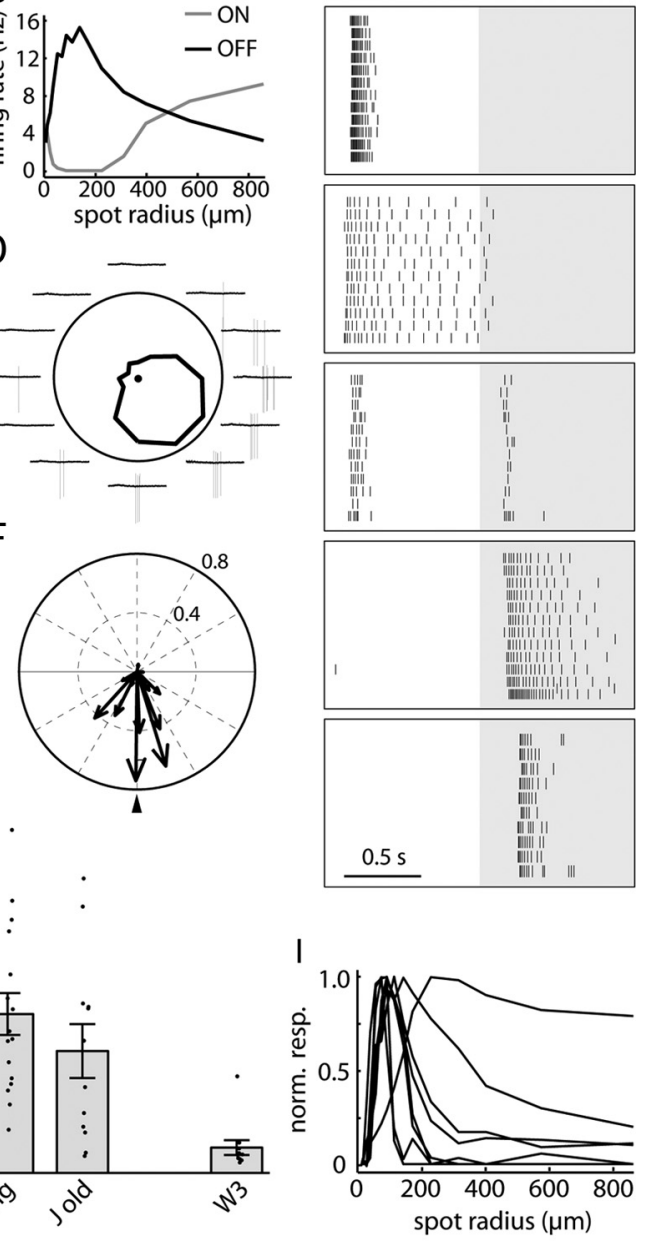

Figure 9. Direction-selective responses of $\operatorname{RGCS}$ persist in old retina. $\boldsymbol{A}, \boldsymbol{B}$, Responses of an old $\mathrm{BD}-\operatorname{RGC}(\boldsymbol{A})$ and an old J-RGC $(\boldsymbol{B})$ to flashing spots as a function of the spot radius. $C, D$, Response of an old $B D-\operatorname{RGC}(\boldsymbol{C})$ and an old $J-\operatorname{RGC}(\boldsymbol{D})$ to small bars moving across their receptive field centers in eight different directions. Plots indicate spikes fired for each direction. $\boldsymbol{E}, \boldsymbol{F}$, Polar summary of the preferred directions of old BD-RGCS $(\boldsymbol{E})$ and J-RGCS $(\boldsymbol{F})$ recorded from well oriented retina. For J-RGCS results are shown in relationship to their dendritic arbor asymmetry (arrowhead). G, Direction selectivity (DS) index for old and young BD- and J-RGCs calculated as described previously (Kim etal., 2008). The DS index ofW3-RGCS, a nondirection selective type, is replotted from Kim etal. (2010) for comparison. $N=$ 22, 6, 16, 12 and 11 for young BD-, old BD-, young J-, old J-, and W3-RGCS, respectively. Error bars indicate the SEM. $\boldsymbol{H}$, Variety of visual responses of RGCs in an aged retina to a flashing spot of optimal size at the receptive field center. Background shading indicates periods when light was off. Each panel is a raster graph of firing from one neuron, and each row is a repeat of the same stimulus. Tickmarks represent action potentials. From top to bottom, RGCs are classified as ON transient, ON sustained, ON-OFF, OFF sustained, and OFF transient. I, Responses of RGCs in an aged retina to a flashing spot as a function of the spot radius. All but one of the cells tested showed surround inhibition as indicated by a decrease in the firing rate as the spot radius increased.

2007), increased retinal area (Harman et al., 2000), and decreased macula thickness (Eriksson and Alm, 2009) in old humans.

Is reduced cell density accompanied by a decrease in the synapses these cells make? In the brain, aging has been associated with reduced synapse number (Dickstein et al., 2007). Similarly, nerve terminal density in the IPL decreased with age (Fig. 5), suggesting that synaptic input to RGCs decreases with age. The age-related increase in retinal area may also contribute to decreased synaptic density, but because the IPL volume changes little with age, it seems likely that there is a decrease in the absolute number of retinal synapses. With increased retinal area, old neurons would need to expand their arbor size to maintain the same connectivity. Such compensatory expansion can occur in young retinas. In chick, for example, ocular enlargement leads to reduction in cell density and enlargement of RGC dendritic arbors (Troilo et al., 1996). In old retina, in contrast, compensation is not observed. Instead, dendritic arbors of most or all RGC subtypes shrink with age (Figs. 6, 7, 11).

Although these effects are highly significant at the population level, they are small in absolute terms: for example, dendritic field diameter decreases $\sim 5 \%$. Our failure to detect changes in the visual receptive fields of individual neurons (Fig. 9) is therefore not unexpected. The structural differences we encountered between young and aged retinas of mouse may thus contribute to but cannot account for all of the profound age-related losses in visual faculties in humans.

The reduction in RGC dendritic field is consistent with age-induced reductions in dendritic extent documented in many (but not all) types of brain neurons (de Brabander et al., 1998; Grill and Riddle, 2002; Markham and Juraska, 2002; Burke and Barnes, 2006), but little is known about the relationship of such changes to degradation of synaptic specificity. We took advantage of the precise laminar structure and physiological accessibility of retinas to test whether aging impacted circuit organization. The sublaminar organization of the IPL was unaffected by age, and RGCs exhibited appropriate responses to specific visual stimuli, reflecting maintenance of complex circuitry within the IPL (Figs. 8, 9).

RGC axons also exhibited age-related changes. Axons remained targeted to the appropriate SC lamina with age, but their arbors were significantly smaller and simpler than their young adult counterparts (Figs. 10, 11). Such alterations have not, to our knowledge, been reported previously, and suggest that signals from old RGCs may be relayed less well to brain targets. Old axons may be affected by age-related decreases in factors implicated in axonal maturation or maintenance such as axonal transport (Karlsson et al., 1992) or complement components (Stevens et al., 2007). More generally, few reports have appeared on age-related changes in central axons; RGCs may be well suited for detailed analysis of such alterations.

Although multiple RGC subtypes exhibited similar agerelated changes, other neuronal types reacted differently. Dendritic arbor size did not change significantly with age in either of the amacrine subtypes analyzed (Fig. 12), and lamination was maintained in all five amacrine populations studied. Rod bipolars exhibited a third pattern: their dendrites sprouted into the photoreceptor layer, as reported previously (Liets et al., 2006; Eliasieh et al., 2007; Terzibasi et al., 2009), but their axons exhibited no obvious alterations. These data show that even within a circuit, different neurons can undergo distinct aging programs. Moreover, within the same neuron, different compartments can show distinct morphological responses to old age.

The diverse cellular changes we document in aged retinas may be tied to visual defects typical of old age, such as reductions in 

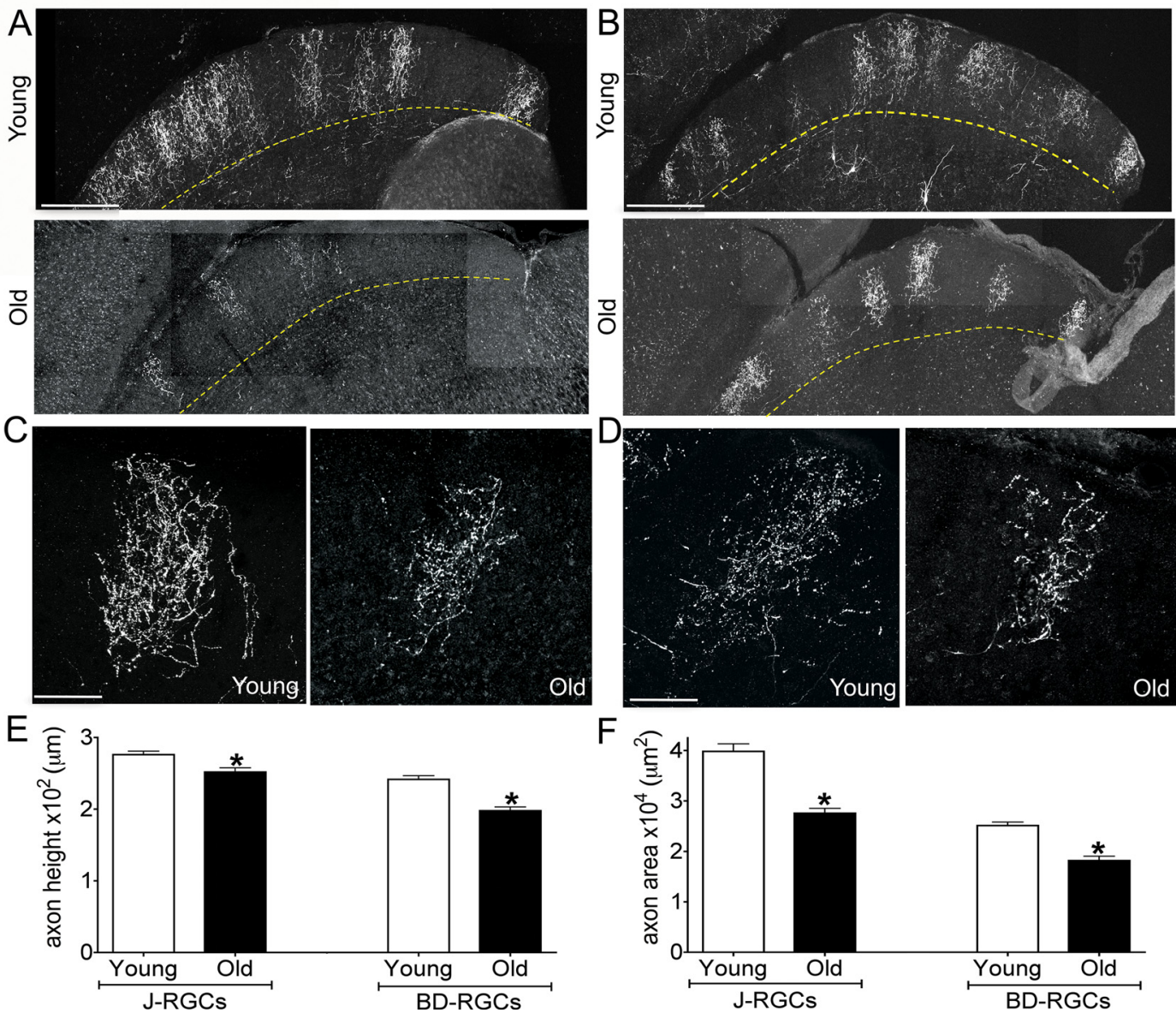

Figure 10. Age-related reduction in the size of $\operatorname{RGC}$ axonal arbors. Axonal arbors of J-RGCs $(\boldsymbol{A}, \boldsymbol{C})$ and $B D-\operatorname{RGCs}(\boldsymbol{B}, \boldsymbol{D})$ in the superior colliculus of young adult and old mice. $\boldsymbol{A}, \boldsymbol{B}, \mathrm{L}$ ow-power images of sagittal sections show that axonal arbors remain confined to the superficial half of the retinorecipient zone. $C, D$, High-power images of single arbors show that arbors are smaller and less dense in old than in young adult mice. $\boldsymbol{E}, \boldsymbol{F}$, Quantitative analysis showed significant age-related decreases in axon height $(\boldsymbol{E})\left(\mathrm{J}\right.$ axons, ${ }^{*} p=0.002 ; \mathrm{BD}$ axons, $\left.{ }^{*} p=0.002\right)$ and axon area $(\boldsymbol{F})\left(\mathrm{J}\right.$ axons, ${ }^{*} p=$ 0.001; BD axons, $\left.{ }^{*} p<0.0001\right) . n=24$ and 38 young and old BD-RGC axons and 28 and 36 young and old J-RGC axons. Scale bars: $A, B, 300 \mu \mathrm{m} ; C, D, 100 \mu \mathrm{m}$.
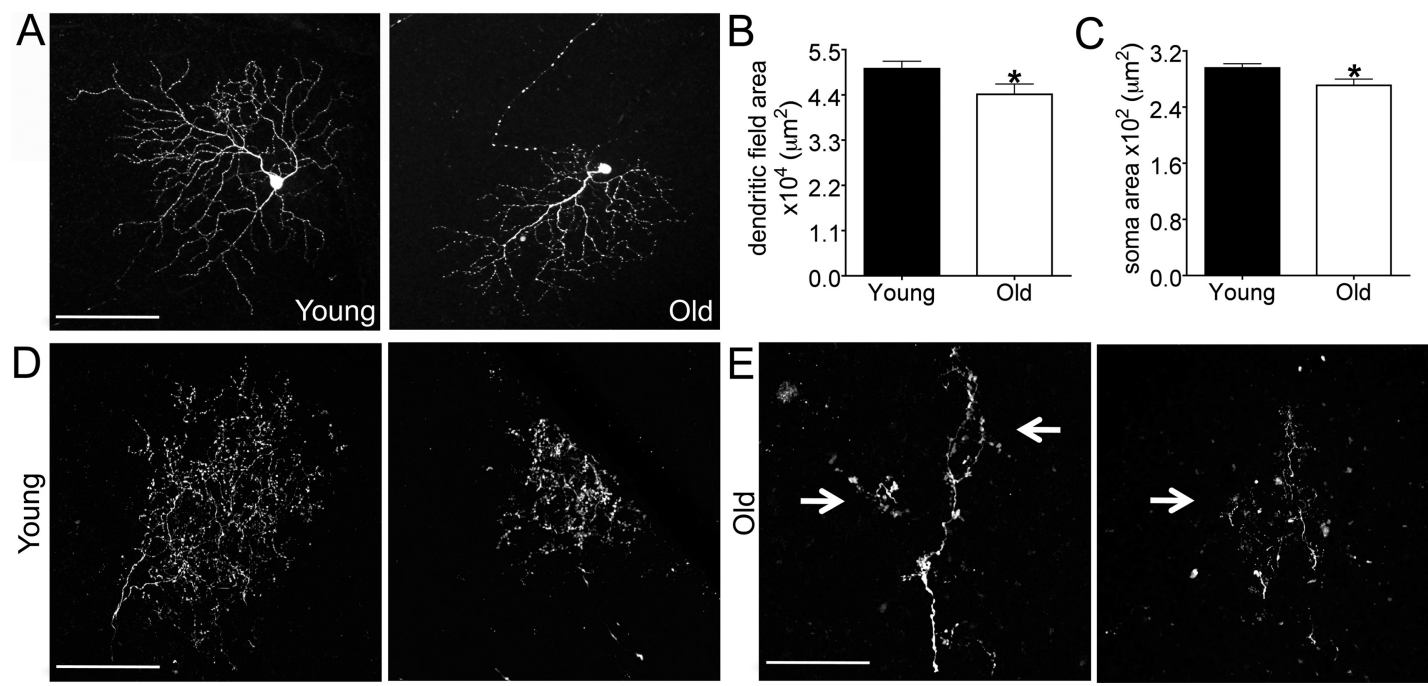

Figure 11. Age-related atrophy of RGC arbors does not result from prolonged YFP expression. Young adult and aged mice were infected with AAV to label RGCs; retinas and superior colliculi were fixed 5- 8 weeks later and imaged. $\boldsymbol{A}$, Labeled RGCs in young adult and old retina. $\boldsymbol{B}, \boldsymbol{C}$, Age-related reduction in the dendritic field area $(\boldsymbol{B}, n=171$ aged and 85 young adult RGCs from at least 8 mice per group; $\left.{ }^{*} p=0.04\right)$ and soma size $\left(\boldsymbol{C}, n=221\right.$ aged and 162 young adult $\left.\mathrm{RGCS} ;{ }^{*} p=0.016\right)$. $\mathbf{D}-\boldsymbol{E}$, Axon arbors in the superior colliculus of young adult and aged mice had markedly reduced dendritic complexities along with abnormal swellings and varicosities (arrows). Scale bar, $100 \mu \mathrm{m}$. 
A
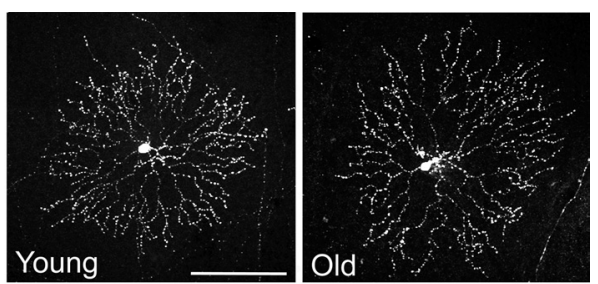

$\mathrm{B}$
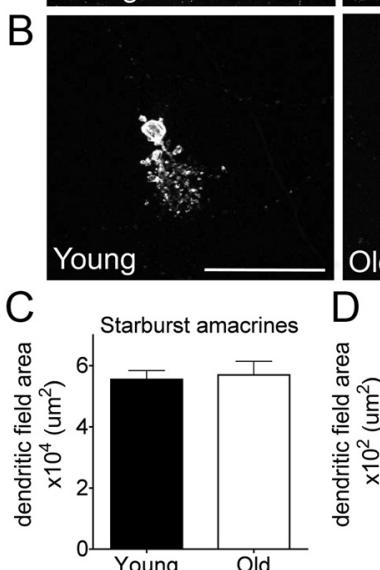
Old

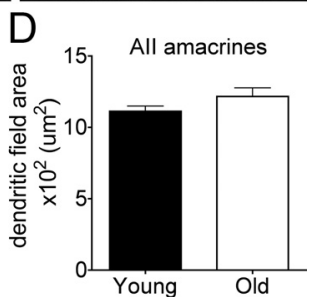

Figure 12. Dendritic area of amacrine cells is maintained in old retina. $A, B$, Starburst $(A)$ and $A l l$ amacrine cells $(\boldsymbol{B})$ labeled with AAV-GFP in young adult and old retina. $\boldsymbol{C}, \boldsymbol{D}$, Dendritic field area of starburst $(\boldsymbol{C})$ and All amacrines $(\boldsymbol{D})$ is unaltered in aged mice $(n=24$ and 10 starburst amacrine arbors and 443 and 53 All amacrine arbors for young and old adults, respectively; ${ }^{*} p=0.79$ for starburst amacrines and $p=0.34$ for All amacrines). Scale bars: $\boldsymbol{A}, 100 \mu \mathrm{m} ; \boldsymbol{B}, 50 \mu \mathrm{m}$.

visual acuity, motion perception, and visual processing speed. Of these alterations, visual acuity defects have been the most widely documented in both humans (Weale, 1975, 1982; Frisén and Frisén, 1981; Owsley et al., 1983; Gittings and Fozard, 1986; Jay et al., 1987) and experimental animals (Ordy et al., 1980; Fite et al., 1991; Kolesnikov et al., 2010). However, the cause of this reduction remains unclear. Optical factors (i.e., decreased pupil size and increased light scatter from lens opacification) are insufficient to account for the loss in acuity, implicating changes in retinal and other neurons (Weale, 1975, 1982). Two neuronal mechanisms have been hypothesized: neuronal loss and structural alternations (Spear, 1993). We found no evidence of cell death but documented age-related increases in retinal area and decreases in RGC dendritic field area. Together, these alterations could lead to gaps in coverage of the visual field by individual RGC subtypes, perhaps contributing to decreased acuity.

Older adults also fare worse than young adults in motion discrimination tests (Sekuler et al., 1980; Wojciechowski et al., 1995; Bennett et al., 2007). In the retina, multiple RGC populations respond selectively to motion in different directions (Oyster et al., 1993; Kay et al., 2011). We examined the physiological properties of two of these direction-selective types, J- and BD-RGCs. Both types remained direction selective in old mice, although old J-RGCs were slightly attenuated in their motion selectivity. Thus, age-related declines in motion detection may not be due to the inherent ability of RGCs to respond to motion but instead may reflect other defects. One such defect may be the reduced complexity and size of old J- and BD-RGC axons, which could compromise the relay of motion information to the brain. Intrinsic cortical defects also seem likely to play a role (Schmolesky et al., 2000). Finally, the reduction in axon size and complexity may participate in the decrease in visual processing speed observed in older adults. If signal transmission from RGCs to brain targets is impaired, the visual system may need more time to accumulate sufficient information.

In conclusion, we have documented numerous quantitative changes in old retina, including decreased area of RGC dendritic and axonal arbors, decreased coverage of the visual field, and decreased density of cells and synapses. In contrast, qualitative features of retinal connectivity, including molecular identity, laminar specificity of arbors in the IPL, and complex responses of RGCs to visual stimuli, were preserved. These results provide support for the hypothesis that subtle alterations in cellular organization or morphology, rather than major alterations in cell number or synaptic specificity are responsible for age-related neuronal dysfunction (Burke and Barnes, 2006; Dickstein et al., 2007). Testing this hypothesis has proven difficult in the tangled neuropil of the brain; the regular organization of the retina and the availability of molecular markers for its cells and synapses facilitated our analysis. These features also allowed us to show that different neurons within a single circuit show distinct agerelated responses and that axonal and dendritic compartments of the same cell can respond differently to aging. Together, our results provide a foundation for using the retina to elucidate molecular mechanisms that underlie these structural changes, determine which changes underlie age-related functional decline, and assess interventions that might attenuate neural aging.

\section{References}

Aggarwal P, Nag TC, Wadhwa S (2007) Age-related decrease in rod bipolar cell density of the human retina: an immunohistochemical study. J Biosci 32:293-298.

Badea TC, Nathans J (2004) Quantitative analysis of neuronal morphologies in the mouse retina visualized by using a genetically directed reporter. J Comp Neurol 480:331-351.

Bennett PJ, Sekuler R, Sekuler AB (2007) The effects of aging on motion detection and direction identification. Vision Res 47:799-809.

Berson DM, Castrucci AM, Provencio I (2010) Morphology and mosaics of melanopsin-expressing retinal ganglion cell types in mice. J Comp Neurol 518:2405-2422.

Bishop NA, Lu T, Yankner BA (2010) Neural mechanisms of ageing and cognitive decline. Nature 464:529-535.

Bridge KE, Berg N, Adalbert R, Babetto E, Dias T, Spillantini MG, Ribchester RR, Coleman MP (2009) Late onset distal axonal swelling in YFP-H transgenic mice. Neurobiol Aging 30:309-321.

Buffelli M, Burgess RW, Feng G, Lobe CG, Lichtman JW, Sanes JR (2003) Genetic evidence that relative synaptic efficacy biases the outcome of synaptic competition. Nature 424:430-434.

Burke SN, Barnes CA (2006) Neural plasticity in the ageing brain. Nat Rev Neurosci 7:30-40.

Coombs J, van der List D, Wang GY, Chalupa LM (2006) Morphological properties of mouse retinal ganglion cells. Neuroscience 140:123-136.

de Brabander JM, Kramers RJ, Uylings HB (1998) Layer-specific dendritic regression of pyramidal cells with ageing in the human prefrontal cortex. Eur J Neurosci 10:1261-1269.

Dickstein DL, Kabaso D, Rocher AB, Luebke JI, Wearne SL, Hof PR (2007) Changes in the structural complexity of the aged brain. Aging Cell 6:275-284.

Dräger UC (1974) Autoradiography of tritiated proline and fucose transported transneuronally from the eye to the visual cortex in pigmented and albino mice. Brain Res 82:284-292.

Eliasieh K, Liets LC, Chalupa LM (2007) Cellular reorganization in the human retina during normal aging. Invest Ophthalmol Vis Sci 48:28242830 .

Eriksson U, Alm A (2009) Macular thickness decreases with age in normal eyes: a study on the macular thickness map protocol in the Stratus OCT. Br J Ophthalmol 93:1448-1452.

Feng G, Mellor RH, Bernstein M, Keller-Peck C, Nguyen QT, Wallace M, Nerbonne JM, Lichtman JW, Sanes JR (2000) Imaging neuronal subsets in transgenic mice expressing multiple spectral variants of GFP. Neuron 28:41-51.

Fite, K.V., Bengston, L. Donaghey, B. (1991) Age, sex, and light damage in 
the avian retina: a model system. In: The changing visual system (Bagnoli P, Hodos W, eds), pp 283-294. New York: Plenum.

Fox MA, Sanes JR (2007) Synaptotagmin I and II are present in distinct subsets of central synapses. J Comp Neurol 503:280-296.

Frisén L, Frisén M (1981) How good is normal visual acuity?. A study of letter acuity thresholds as a function of age. Albrecht Von Graefes Arch Klin Exp Ophthalmol 215:149-157.

Gao H, Hollyfield JG (1992) Aging of the human retina. Differential loss of neurons and retinal pigment epithelial cells. Invest Ophthalmol Vis Sci 33:1-17.

Gittings NS, Fozard JL (1986) Age related changes in visual acuity. Exp Gerontol 21:423-433.

Glorioso C, Sibille E (2011) Between destiny and disease: genetics and molecular pathways of human central nervous system aging. Prog Neurobiol 93:165-181.

Grill JD, Riddle DR (2002) Age-related and laminar-specific dendritic changes in the medial frontal cortex of the rat. Brain Res 937:8-21.

Harman A, Abrahams B, Moore S, Hoskins R (2000) Neuronal density in the human retinal ganglion cell layer from 16-77 years. Anat Rec 260:124-131.

Hedden T, Gabrieli JD (2004) Insights into the ageing mind: a view from cognitive neuroscience. Nat Rev Neurosci 5:87-96.

Hofbauer A, Dräger UC (1985) Depth segregation of retinal ganglion cells projecting to mouse superior colliculus. J Comp Neurol 234:465-474.

Hong YK, Kim IJ, Sanes JR (2011) Stereotyped axonal arbors of retinal ganglion cell subsets in the mouse superior colliculus. J Comp Neurol 519:1691-1711.

Huberman AD, Wei W, Elstrott J, Stafford BK, Feller MB, Barres BA (2009) Genetic identification of an On-Off direction-selective retinal ganglion cell subtype reveals a layer-specific subcortical map of posterior motion. Neuron 62:327-334.

Jackson GR, Owsley C (2003) Visual dysfunction, neurodegenerative diseases, and aging. Neurol Clin 21:709-728.

Jay JL, Mammo RB, Allan D (1987) Effect of age on visual acuity after cataract extraction. Br J Ophthalmol 71:112-115.

Karlsson JO, Inomata M, Kawashima S (1992) Slow axonal transport of soluble proteins and calpain in retinal ganglion cells of aged rabbits. Neurosci Lett 141:127-129.

Katz ML, Robison WG Jr (1986) Evidence of cell loss from the rat retina during senescence. Exp Eye Res 42:293-304.

Kay JN, De la Huerta I, Kim IJ, Zhang Y, Yamagata M, Chu MW, Meister M, Sanes JR (2011) Retinal ganglion cells with distinct directional preferences differ in molecular identity, structure, and central projections. J Neurosci 31:7753-7762.

Kim CB, Tom BW, Spear PD (1996) Effects of aging on the densities, numbers, and sizes of retinal ganglion cells in rhesus monkey. Neurobiol Aging $17: 431-438$

Kim IJ, Zhang Y, Yamagata M, Meister M, Sanes JR (2008) Molecular identification of a retinal cell type that responds to upward motion. Nature 452:478-482.

Kim IJ, Zhang Y, Meister M, Sanes JR (2010) Laminar restriction of retinal ganglion cell dendrites and axons: subtype-specific developmental patterns revealed with transgenic markers. J Neurosci 30:1452-1462.

Kolesnikov AV, Fan J, Crouch RK, Kefalov VJ (2010) Age-related deterioration of rod vision in mice. J Neurosci 30:11222-11231.

Kong JH, Fish DR, Rockhill RL, Masland RH (2005) Diversity of ganglion cells in the mouse retina: unsupervised morphological classification and its limits. J Comp Neurol 489:293-310.

Lefebvre JL, Zhang Y, Meister M, Wang X, Sanes JR (2008) gammaProtocadherins regulate neuronal survival but are dispensable for circuit formation in retina. Development 135:4141-4151.

Liets LC, Eliasieh K, van der List DA, Chalupa LM (2006) Dendrites of rod bipolar cells sprout in normal aging retina. Proc Natl Acad Sci U S A 103:12156-12160.

Markham JA, Juraska JM (2002) Aging and sex influence the anatomy of the rat anterior cingulate cortex. Neurobiol Aging 23:579-588.

Masland RH (2001) The fundamental plan of the retina. Nat Neurosci $4: 877-886$.

Miller AK, Alston RL, Mountjoy CQ, Corsellis JA (1984) Automated differential cell counting on a sector of the normal human hippocampus: the influence of age. Neuropathol Appl Neurobiol 10:123-141.

Mooney RD, Rhoades RW (1990) Relationships between physiological and morphological properties of retinocollicular axons in the hamster. J Neurosci 10:3164-3177.

Morrison JC, Cork LC, Dunkelberger GR, Brown A, Quigley HA (1990) Aging changes of the rhesus monkey optic nerve. Invest Ophthalmol Vis Sci 31:1623-1627.

Morrison JH, Hof PR (1997) Life and death of neurons in the aging brain. Science 278:412-419.

Nagai T, Yamada S, Tominaga T, Ichikawa M, Miyawaki A (2004) Expanded dynamic range of fluorescent indicators for $\mathrm{Ca}^{2+}$ by circularly permuted yellow fluorescent proteins. Proc Natl Acad Sci U SA 101:10554-10559.

Ordy JM, Brizzee KR, Hansche J (1980) Visual acuity and foveal cone density in the retina of the aged rhesus monkey. Neurobiol Aging 1:133-140.

Owsley C, Sekuler R, Siemsen D (1983) Contrast sensitivity throughout adulthood. Vision Res 23:689-699.

Oyster CW, Amthor FR, Takahashi ES (1993) Dendritic architecture of ONOFF direction-selective ganglion cells in the rabbit retina. Vision Res 33:579-608.

Peichl L, Ott H, Boycott BB (1987) Alpha ganglion cells in mammalian retinae. Proc R Soc Lond B Biol Sci 231:169-197.

Provencio I, Rollag MD, Castrucci AM (2002) Photoreceptive net in the mammalian retina. This mesh of cells may explain how some blind mice can still tell day from night. Nature 415:493.

Richard MB, Taylor SR, Greer CA (2010) Age-induced disruption of selective olfactory bulb synaptic circuits. Proc Natl Acad Sci USA 107:15613-15618.

Rodieck RW (1991) The density recovery profile: a method for the analysis of points in the plane applicable to retinal studies. Vis Neurosci 6:95-111.

Sanes JR, Zipursky SL (2010) Design principles of insect and vertebrate visual systems. Neuron 66:15-36.

Schmolesky MT, Wang Y, Pu M, Leventhal AG (2000) Degradation of stimulus selectivity of visual cortical cells in senescent rhesus monkeys. Nat Neurosci 3:384-390.

Sekuler R, Hutman LP, Owsley CJ (1980) Human aging and spatial vision. Science 209:1255-1256.

Smith DE, Rapp PR, McKay HM, Roberts JA, Tuszynski MH (2004) Memory impairment in aged primates is associated with focal death of cortical neurons and atrophy of subcortical neurons. J Neurosci 24:4373-4381.

Spear PD (1993) Neural bases of visual deficits during aging. Vision Res 33:2589-2609.

Stevens B, Allen NJ, Vazquez LE, Howell GR, Christopherson KS, Nouri N, Micheva KD, Mehalow AK, Huberman AD, Stafford B, Sher A, Litke AM, Lambris JD, Smith SJ, John SW, Barres BA (2007) The classical complement cascade mediates CNS synapse elimination. Cell 131:1164-1178.

Swaab DF, FliersE, Partiman TS (1985) The suprachiasmatic nucleus of the human brain in relation to sex, age and senile dementia. Brain Res 342:37-44.

Terry RD, DeTeresa R, Hansen LA (1987) Neocortical cell counts in normal human adult aging. Ann Neurol 21:530-539.

Terzibasi E, Calamusa M, Novelli E, Domenici L, Strettoi E, Cellerino A (2009) Age-dependent remodelling of retinal circuitry. Neurobiol Aging 30:819-828.

Trachimowicz RA, Fisher LJ, Hinds JW (1981) Preservation of retinal structure in aged pigmented mice. Neurobiol Aging 2:133-141.

Troilo D, Xiong M, Crowley JC, Finlay BL (1996) Factors controlling the dendritic arborization of retinal ganglion cells. Vis Neurosci 13:721-733.

Valdez G, Tapia JC, Kang H, Clemenson GD Jr, Gage FH, Lichtman JW, Sanes JR (2010) Attenuation of age-related changes in mouse neuromuscular synapses by caloric restriction and exercise. Proc Natl Acad Sci U S A 107:14863-14868.

Wässle H (2004) Parallel processing in the mammalian retina. Nat Rev Neurosci 5:747-757.

Wässle H, Puller C, Müller F, Haverkamp S (2009) Cone contacts, mosaics, and territories of bipolar cells in the mouse retina. J Neurosci 29:106-117.

Weale RA (1975) Senile changes in visual acuity. Trans Ophthalmol Soc U K 95:36-38.

Weale RA (1982) Senile ocular changes, cell death, and vision. In: Aging and human visual function (Sekuler R, Kline D, Dismukes K, eds), pp 161171. New York: Liss.

Weisse I (1995) Changes in the aging rat retina. Ophthalmic Res 27 [Suppl 1]:154-163.

Wojciechowski R, Trick GL, Steinman SB (1995) Topography of the agerelated decline in motion sensitivity. Optom Vis Sci 72:67-74. 